\title{
Echocardiographic evaluation of 'sandwich plug' closure of mechanical aortic valve at left ventricular assist device implantation
}

\author{
Amanda Kleiman, ${ }^{1}$ Daniel A Smith, ${ }^{1}$ Leora T Yarboro, ${ }^{2}$ John S McNeil ${ }^{1}$
}

'Department of Anesthesiology, University of Virginia, Charlottesville, Virginia, USA ${ }^{2}$ Department of Surgery, University of Virginia, Charlottesville, Virginia, USA

\section{Correspondence to} Dr Amanda Kleiman, ak8zg@hscmail.mcc.virginia.edu

Accepted 17 January 2018

\section{DESCRIPTION}

A 67-year-old man with a history of non-ischaemic cardiomyopathy (ejection fraction 15\%-20\%) and previous mechanical aortic valve replacement presented for HeartMate II left ventricular assist device (LVAD) implantation due to worsening heart failure symptoms (New York Heart Association III-IV). After redo sternotomy, the aortic valve was closed with a prefashioned occluder device (figure 1). After occluder placement, the aortic cross-clamp was removed and the valve assessed with transoesophageal echocardiography (TOE) to ensure proper closure (figures 2-4, videos 1-3). Once satisfactory closure was confirmed, a HeartMate II LVAD was inserted.

The presence of a mechanical prosthesis is associated with an increased risk of thromboembolic complications and considered a relative contraindication for LVAD. A bypassed, intermittently opening prosthetic valve carries a prohibitive risk of thromboembolic complications, despite anticoagulants. ${ }^{1}$ Additionally, aortic insufficiency increases the mechanical work required from the LVAD. For the patient with a mechanical aortic valve who requires LVAD placement, there is debate as to the best approach as, unlike biological valves, mechanical valves cannot be easily closed. Some surgeons recommend replacement with a biological valve; however, this adds complexity to the procedure, worsens outcomes and may not completely reduce the risk of thromboembolism. ${ }^{2}$ Others advocate for placement of an autologous pericardial patch covering the mechanical valve. Another option is to leave the prosthesis in place and increase the

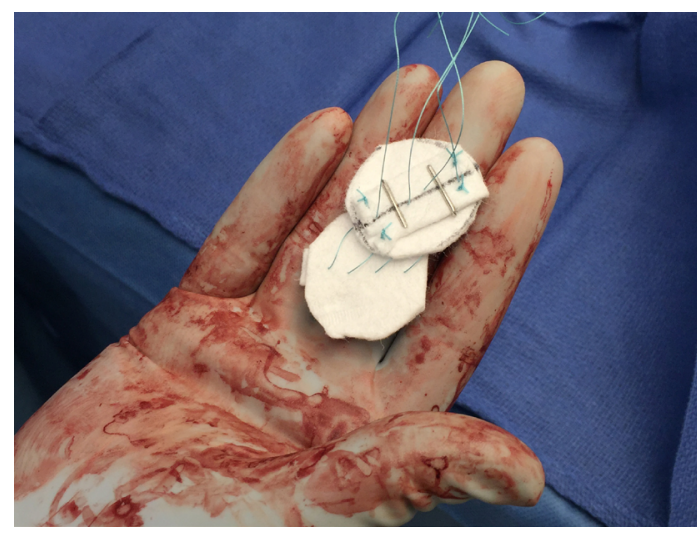

Figure 1 Mechanical aortic valve prosthesis occluder constructed of felt, braided polyester sutures, and vascular clips prior to implantation.

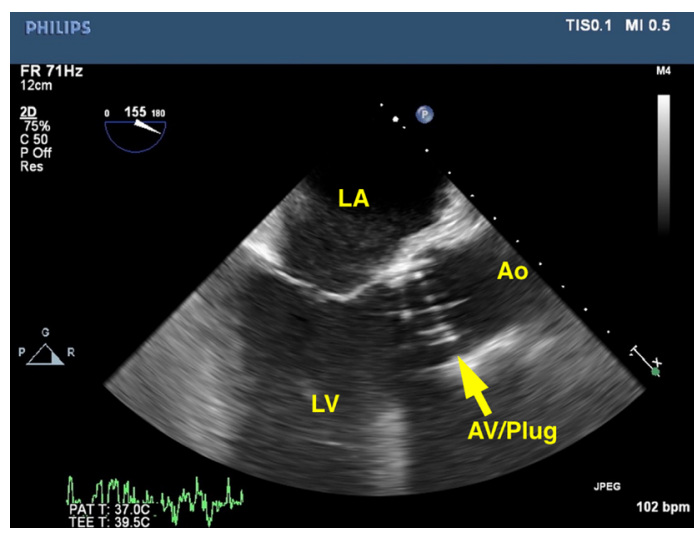

Figure 2 The mid-oesophageal aortic valve long-axis view confirming complete occlusion/closure of the aortic valve without leaflet motion. $\mathrm{Ao}$, aorta; $\mathrm{AV}$, aortic valve; $L A$, left atrium; LV, left ventricle.

level of anticoagulation combined with an attempt to regulate the pump speed to assure some blood flow across the prosthesis. However, this option increases the risk of bleeding.

In 2011, Cohn and Frazier published a technique using a prefashioned occluder constructed of felt, braided polyester sutures, and vascular clips to cinch closed the aortic valve (figure 1). ${ }^{3}$ This technique enables rapid and secure closure in patients with mechanical bileaflet aortic valves. ${ }^{3}$ TOE evaluation of appropriate closure is essential prior to placement of the LVAD. Assessment includes two-dimensional

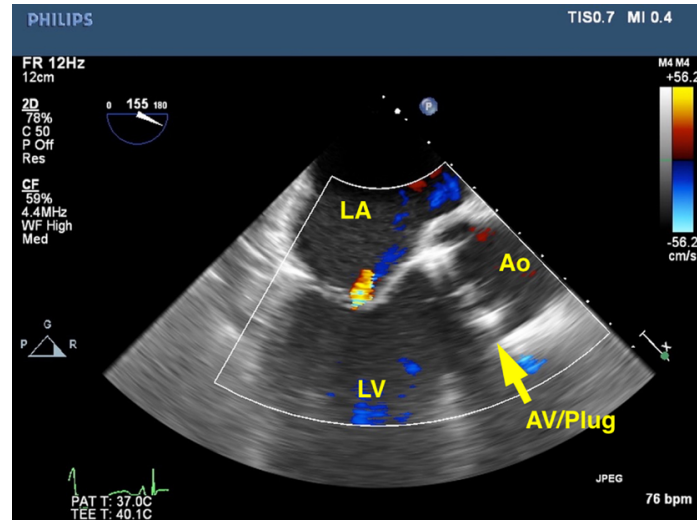

Figure 3 Colour flow Doppler across the left ventricular outflow tract (LVOT) in the mid-oesophageal aortic valve long-axis view confirmed a lack of flow across the LVOT and complete closure of the mechanical valve. Ao, aorta; $A V$, aortic valve; $L A$, left atrium; $L V$, left ventricle. 


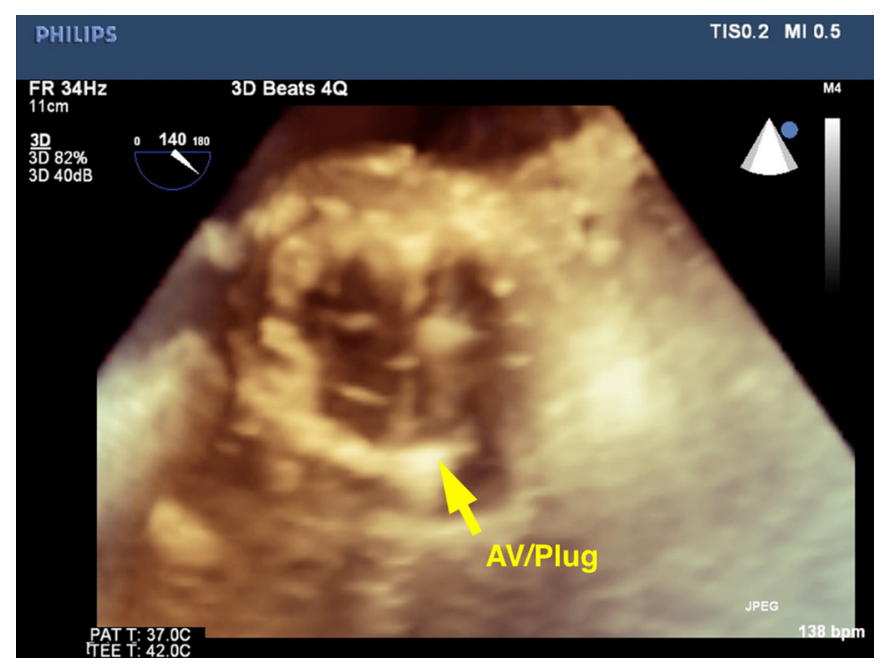

Figure 4 Three-dimensional echocardiography of the aortic valve enables further evaluation of the valve and improved visualisation of occluder placement and prohibition of leaflet motion. AV, aortic valve.

evaluation of the mechanical valve leaflets in the mid-oesophageal aortic valve long-axis view without (figure 2, video 1 ) and with (figure 3, video 2) colour flow Doppler to determine leaflet motion and flow across the valve, respectively. If shadowing from the mechanical valve interferes with image interpretation, the mid-oesophageal aortic valve short-axis view may be used. Three-dimensional echocardiography, if available, is useful to confirm closure without leaflet movement and help visualise the exact location of the plug in relation to the annulus and leaflets if repositioning is required (figure 4 , video 3 ).

Compared with other techniques, the prefashioned occluder is an expedient method of valve closure taking only 2-3 min. ${ }^{3}$ The occluder is created prior to bypass limiting bypass and cross-clamp times which are lengthier when using a pericardial patch which must be sewn into place. ${ }^{2}$ Due to the complexity of the occluder, potential disadvantages include a risk of mechanical failure of the device or movement of the occluder on the valve, though no failures have been described at our centre or by the original developers of the

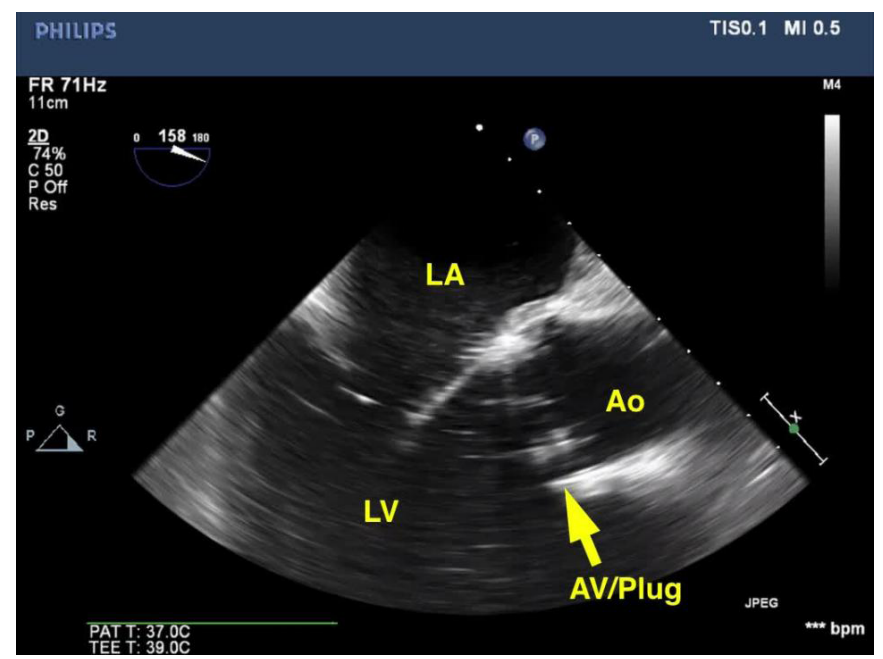

Video 1 The mid-oesophageal aortic valve long-axis view confirming complete occlusion/closure of the aortic valve without leaflet motion. Ao, aorta; AV, aortic valve; LA, left atrium; LV, left ventricle.

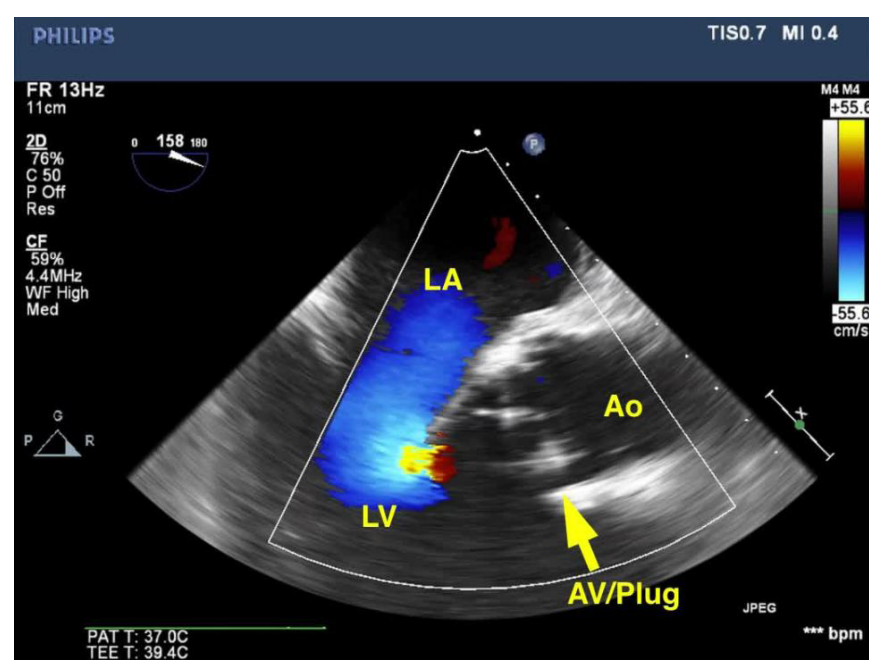

Video 2 Colour flow Doppler across the left ventricular outflow tract (LVOT) in the mid-oesophageal aortic valve long-axis view confirmed a lack of flow across the LVOT and complete closure of the mechanical valve. Ao, aorta; $A V$, aortic valve; $L A$, left atrium; $L V$, left ventricle.

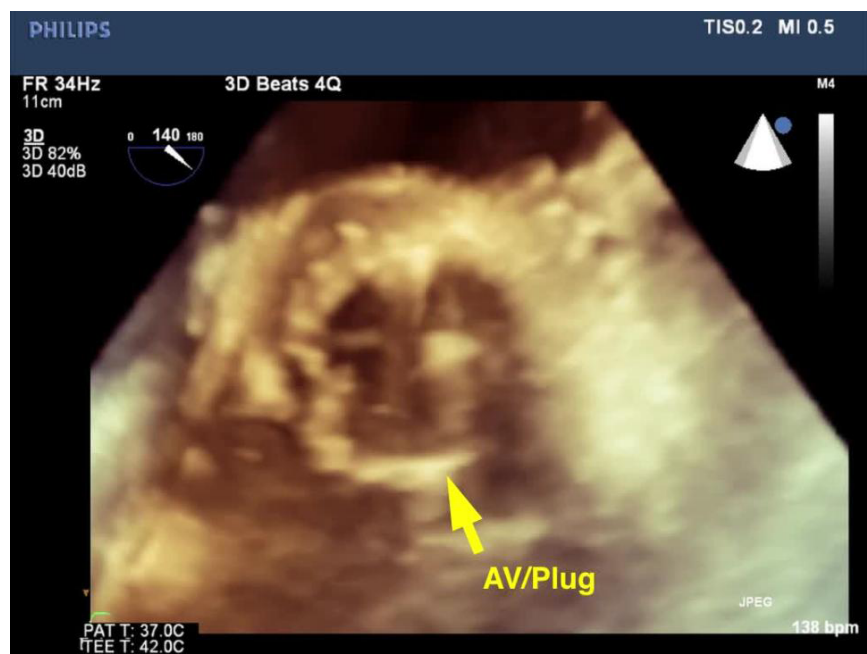

Video 3 Three-dimensional echocardiography of the aortic valve enables further evaluation of the valve and improved visualisation of occluder placement and prohibition of leaflet motion. AV, aortic valve.

technique. ${ }^{3}$ Overall, the ease of placement makes the described prefashioned occluder an attractive option for mechanical valve closure.

\section{Learning points}

- Presence of a mechanical prosthesis is associated with an increased risk of thromboembolic complications and considered a relative contraindication for left ventricular assist device (LVAD). The mechanical prosthesis may be closed with a prefashioned occluder.

- Echocardiographic evaluation of appropriate closure is essential prior to placement of the LVAD.

- Assessment includes evaluation of the mechanical valve leaflets in the mid-oesophageal aortic valve long-axis view with and without colour flow Doppler to determine leaflet motion and flow across the valve, respectively. 
Contributors AK provided intraoperative care and designed and wrote the manuscript. DAS wrote the manuscript. LTY performed the surgical procedure and edited the manuscript. JSM wrote and edited the manuscript.

Funding This research received no specific grant from any funding agency in the public, commercial or not-for-profit sectors.

Competing interests None declared.

Patient consent Obtained.

Provenance and peer review Not commissioned; externally peer reviewed.

(c) BMJ Publishing Group Ltd (unless otherwise stated in the text of the article) 2018. All rights reserved. No commercial use is permitted unless otherwise expressly granted.

\section{REFERENCES}

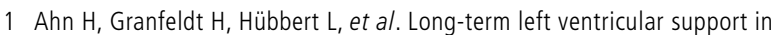
patients with a mechanical aortic valve. Scand Cardiovasc J 2013;47:236-9.

2 Robertson JO, Naftel DC, Myers SL, et al. Concomitant aortic valve procedures in patients undergoing implantation of continuous-flow left ventricular assist devices: an INTERMACS database analysis. J Heart Lung Transplant 2015;34:797-805

3 Cohn WE, Frazier OH. The sandwich plug technique: simple, effective, and rapid closure of a mechanical aortic valve prosthesis at left ventricular assist device implantation. J Thorac Cardiovasc Surg 2011;142:455-7.

Copyright 2018 BMJ Publishing Group. All rights reserved. For permission to reuse any of this content visit http://group.bmj.com/group/rights-licensing/permissions.

BMJ Case Report Fellows may re-use this article for personal use and teaching without any further permission.

Become a Fellow of BMJ Case Reports today and you can:

- Submit as many cases as you like

- Enjoy fast sympathetic peer review and rapid publication of accepted articles

- Access all the published articles

- Re-use any of the published material for personal use and teaching without further permission

For information on Institutional Fellowships contact consortiasales@bmjgroup.com

Visit casereports.bmj.com for more articles like this and to become a Fellow 